\title{
Seamlessness as Disenfranchisement: The Digital State of Pigs and How to Resist ${ }^{1}$
}

\author{
Wolfgang Drechsler \\ Smart City Centre of Excellence (FinEst Twins) \& \\ Ragnar Nurkse Department of Innovation and Governance, \\ Tallinn University of Technology \\ Akadeemia tee 3 \\ Tallinn 12618, Estonia \\ Email: wolfgang.drechsler@taltech.ee
}

\begin{abstract}
If it is the tendency of technology, and especially of information and communication technology, particularly in the context of the smart city, not to empower the human person but rather to disenfranchise them by curtailing their capability to judge and choose, how can one counter this dynamic? Code, make, talk, and pray are suggested as possible modes of resistance.
\end{abstract}

Keywords: El Greco, Friedrich Georg Jünger, Hans-Georg Gadamer, information and communication technology, Juri Lotman, Plato, smart city, social media, technology

\section{Introduction}

The world, at least the Western world and thus global-Western reality as we inhabit it, albeit to various degrees, builds on a legacy, if by now largely tacitly, of Christianity, ancient Greek civilization, and the Enlightenment. Technology was originally only a part, even a small part, of the latter; during the last two centuries, however, the technology logic took over and came to dominate.

The by now agreed-upon political form of governance within that globalWestern tradition that evolved-democracy, and ideally liberal democracy,

1 This work has been supported by the European Commission through the H2020 project 'Finest Twins' (grant no. 856602). 
often in a republican form-is these days under duress from various sides, not least from a recent, terrible track record in several leading Western countries in getting decent, even functional leaders elected. But as an ideal, as a promise, it is still maintained both in Europe and in the former European colonies that constitute the overwhelming part of what is often referred to as the First World. And this form of governance, in turn, is premised on the idea that people, all people, both can and must make up their own mind. This is an approach closely associated with Immanuel Kant (1784), whose thinking is much more at the basis of modern global-Western living-together in a structured form than AngloAmerican experts are often aware of.

The problem is now that Kant's enlightened individual, the basis of his anthropology, is also the foundation of the Western constitutional state. If the capacity of that individual to decide, vote, or at least consent is limited or becomes more limited, then the entire edifice is endangered and in fact needs to be reconsidered, as it would then head towards dysfunctionality and illegitimacy. This is why anything that takes away humans' capacity to make up their own minds is so disastrous-very quickly, the reduction of people to cattle requires, and produces, shepherds (Plat. polit.), if not the other way round.

\section{Disenfranchisement}

Technology —at least a large and significant part of it and to a large and significant extent-precisely reduces that capacity to make up one's own mind. What is worse, it is in fact designed to do so, partially for commercial, partially for power reasons, partially because it is possible. As Manuel Castells (2009) has reminded us, it is wise in this as in any political context to ask the cui bono question, meaning, in whose interest is it? We live in the information and communication technology (ICT) age, and that means that the technology of our times at all levels is ICT, as Carlota Perez (2002) has made particularly clear. And the nexus where $\mathrm{I}$ and $\mathrm{C}$ meet are social media in the widest sense.

The entire idea, the business model of social media, is, in turn, to anticipate or create what people may want and to commercialize this-Zuboff's (2019) surveillance capitalism. There are no technologies that are or remain free from a profit motive, and the business model of social media is making money from the knowledge about the human person. But by doing so, the human person is being 
streamlined. If I only see what entertains me and/or what my friends see and like as well, then I gradually lose my judgment power. That has been the case with, e.g., advertising for a long time, but ICT makes it possible to create and refine an iron cage within which this is happening.

Alongside F. G. Jünger (1949), one could argue that by its very nature technology already has that trajectory towards taking over from human agency; this is then exacerbated by people in whose interest this is.

And who are these people? If we look at that umbrella term for a technologically driven and coordinated society, the smart city — which really is the ICT city—, we can see that there are three groups of people who are interested in it, dominate it and push it on the world. These are business people, who want to exploit; politicians, who want to attain or retain power; and engineers, who do this because they can. Now, of course these are ideal types, and very often, if not usually, we find combinations of these three to various extents. What is important is that there is no human agency in the sense of agency of the citizens here, and that the entire setup is by default about taking citizen agency away.

In cities in which there is a genuine mandate of the government and especially the bureaucracy to take care of people's things for them, this may be OKSingapore comes to mind here, although it is fading these days. But this is not the Western way. At a conference in Singapore a while ago, I heard a government representative say that "agencies are coming together to deliver seamless, anticipatory and personalized services for citizens and businesses" (Yeo, 2019). That is convenient, but it is no excuse in the democratic context that something is detrimental to opinion-shaping but convenient; there is no place for the idiotes - the idiot not interested in public affairs—in Greek-based democracy.

But if we look at our title, it is seamlessness that is of particular interest to us today. Seamlessness means that public services are rendered to citizens, or users, in a seamless way, meaning that I don't have to do anything twice when communicating with the public sector, the bureaucracy (which is the state in action lest we forget!), that filling out forms is done automatically for us, that there is a once-only principle of information provision and so on. It means that services are given to the people without them even requesting them; this is often referred to as the present-day optimal way of how to restructure public services. It is not necessary to ask anymore; services are provided anticipatorily. However, it is exactly at the seams, exactly at the breaking points where human agency can manifest itself and where people can change their track records, their interests. 
If I go to my usual café and always order an Einspänner or a Kapuziner or whatever coffee specialty it may be-these days, ordering my usual Grande Decaf Iced Latte at my Starbucks outlet-after a while, the waiter will bring me, or the barista will bag me, that coffee without asking. And it may well be that this is very convenient, and it even gives me some idea of belonging in a time when there is so little of that. However, it may very well be that at some point, I would like to get something else; maybe I changed my style, my taste, my diet; maybe I would just like to try something else. But I might not even bother asking for it because the system is now geared in such a way that I do not second-guess and change my old preferences. That means I become a slave of my habit, and it is actually the waiter, the human algorithm, who is in control. And he might have good intentions, but also for him this is more efficient and easier, i.e., it is in his interest and not mine. And sure I could rebel, but this would need an act of mine.

Now, as regards coffee, that may be regrettable for a truly full life, but concerning democracy and identity, there is no excuse for this whatsoever. First, in the public sphere, what if there is wrong data-in any sense of the word-that I cannot correct, for whatever reason? Second, and more germane to our line of argument here, pace party democracy, there is no duty to always accept the same type of coffee, but I actually have a duty to make up my own mind in the public sphere. Yes indeed, public service provision seems to be on a lower level than democratic decision-making, but it really isn't. It is the vital way in which I encounter the state, and not only do I have the right to change, to reassess, to reimagine and reinvent myself and my arrangements at any point, I am actually expected to do this.

My not holding the state accountable and trusting that it and its algorithms deliver the optimal services to me-premised as they have to be on whatever is in my own and my fellow citizens' best interests-will in the end also dismantle and incapacitate the state as far as its relations with independent citizens are concerned. Historically and also currently, we have no reason to believe that the state will act in an effective, efficient and equitable way-at least not in the West, at least not anymore-without being held accountable; the neoliberal reforms of the 1990s with their managerialist, numbers- and not people-driven automatisms have, for one, made sure of that. It may very well work in Singapore, and it may very well work in other contexts as well, but it doesn't work "here". 


\section{Seamlessness}

Seamlessness is therefore not a good word because it designates a bad, if and because convenient, thing. Those with a classical or traditional education or background might actually sense this otherwise as well; it is rather indicative that seamlessness is presented by its protagonists as something so positive. In the Western tradition, it is not. What now follows is a rather if not speculative, then somewhat abductive train of thought, because seamlessness as such is not so bad, but it occurs in the worst possible context, and with one of the worst possible penumbras, in one part of the Western tradition.

And this is the story of the Holy Robe, most prominently known as the "Seamless Robe of Jesus", as even Wikipedia (n.d.) has it. That robe is the gown that Jesus Christ wore when he was captured by the minions of the Sanhedrin, and of which he was stripped before the crucifixion. It is, if you will, the piece of cloth, in a certain sense the central piece, in the worst moment of Western civilization traditionally understood. The crucifixion, in spite of it being the road to resurrection, to saving mankind, nonetheless is religiously the murder of God, the worst possible sin, and in another sense, of course, an absolutely terrible moment of humiliation, of torture, and of violent death.

One of the most famous works of Western art, a truly iconic piece, even in a literal sense, depicts this. It is one of the great Spanish paintings of the Golden Age of that art, El Greco's 'The Disrobing of Christ', which still hangs in the sacristy of the church in Toledo for which it was commissioned and painted (Fig. 1).

This intense, color-bursting masterpiece puts the robe at the center of our attention. Everything else flows from the cloth. It is a tremendously impressive piece of art, and once again, those participating in the heritage of which this painting is a part surely have it in front of their eyes when they recall it. I myself was very lucky to see it when visiting Toledo as a boy with my parents many decades ago, and the impression of horrendous grandeur has never been forgotten.

And the point is that this robe is the incarnation, the celebration, the iconic representation of seamlessness. This is the seamless gown. This is seamlessness. Once again, this in itself is not supposed to be something bad; by being the robe, the last gown of Jesus before he ascended into the kerygma becoming 


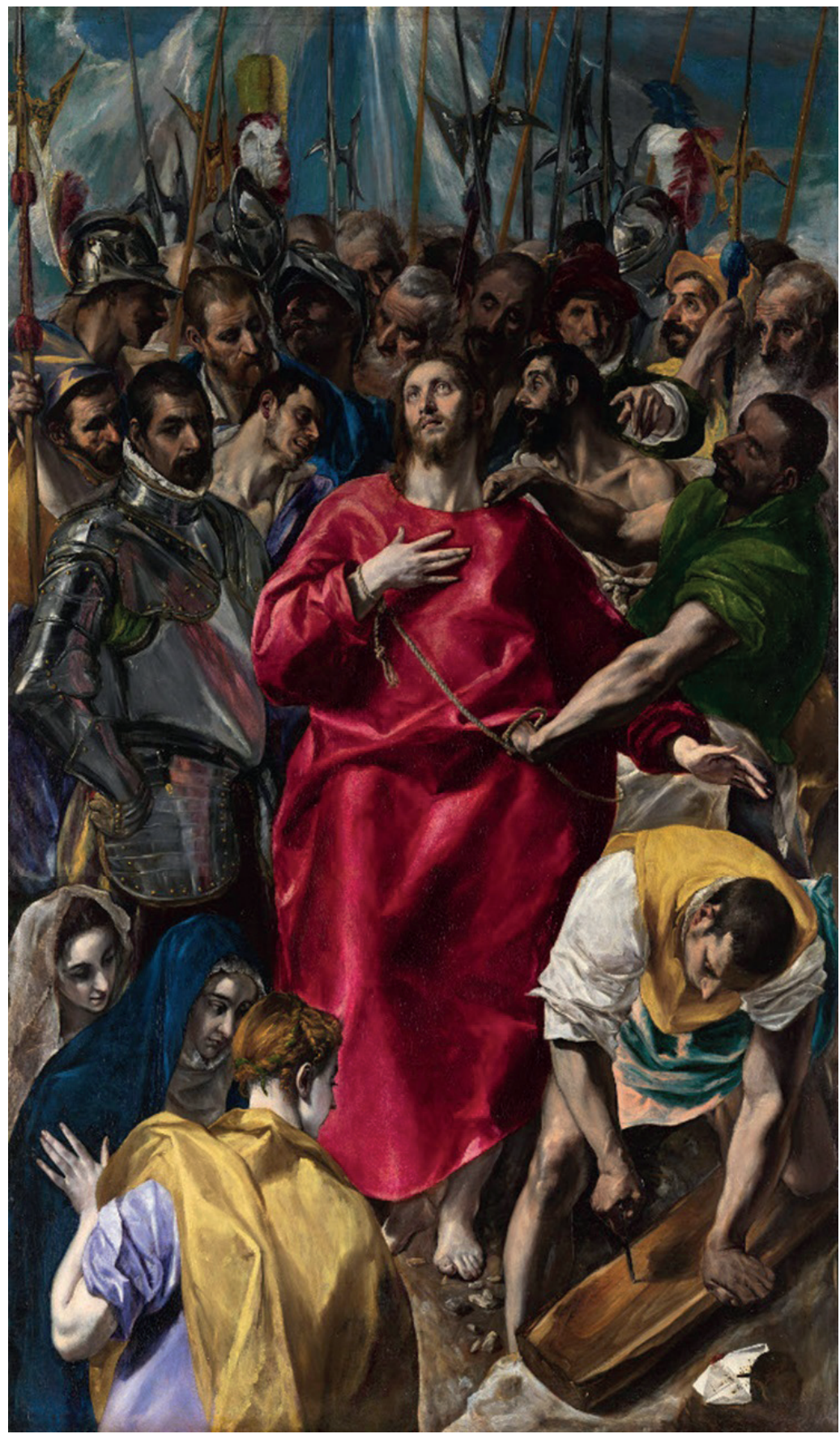

Figure 1. ‘The Disrobing of Christ' or ‘El Expolio’ by El Greco (1577-1579). 
Christ, in a certain sense it is even the symbol of the built church, of vitrage and of Domschatz. However, nobody with some sensitivity can deny that it is this moment, perhaps this painting, that conjures up in our minds the atmosphere of meaning, the connotation of seamlessness. Seamlessness stands for death, for spoliation, for inhuman horror.

Now, it can very well be argued that this is something that engineers don't know, businessmen don't need to know, and politicians may easily pretend not to know. But it seems that that penumbra of meaning actually guides us along the right path. Once we understand that it is the seam at which human agency becomes possible in the technological world, we realize the horrors of seamlessness. We do become genuinely dehumanized by seamlessness, because humanity means agency, and agency is denied through seamlessness. I cannot change my mind, I cannot change my desire, I cannot grow, I cannot change. This is what seamlessness means in the context of the ICT life that is being constructed today for us, and against us. Seamlessness is a dehumanizing prison of our times.

\section{The state of pigs}

Why this is so is further elucidated by that second pillar of Western civilization, the Greek one. We have already seen how the science, how the engineering part of the enlightenment, in its ugly, totalizing manifestation, takes over the, not always successful but certainly ethically geared, heritage of the occident, and we have already seen what the imagery of the Christian legacy can contribute here. But what is so disenfranchising about seamlessness, about the abrogation of agency, can perhaps be illustrated best by one of the best known tropes or episodes of the classical Greek philosophical tradition as well.

And while the Western practical political world rests on the thought of Aristotle, surely the less pragmatic, but more exciting thought of Plato, with its high flights, complicated constructions and breathtaking reframings of human existence has dominated theory. But also for Plato, the highest form of philosophizing was political philosophy. He even tried praxis himself; how he did in Syracuse, everyone knows or should know. Plato wrote three books of political philosophy, of which the Politeia, often if wrongly translated as the Republic, is by far the most prominent, the most famous one. I myself belong to those, along with my philosophical teacher Hans-Georg Gadamer, who think that this is a heuristic 
utopia, not the plan for a society that Plato ever wanted to be manifest in reality. Rather, it is a book that is supposed to lead us to insight (Gadamer, 1934). And the effects of seamlessness, what it is for our way of structurally living-together in time and space, is illustrated by a Politeia concept. Likewise, it is not actually the meaning of that passage, of that scenario, but it is the meaning of what it evokes.

And that is the state of pigs (Plat. polit. II 369-373, esp. 372d, 373c). Plato wants to describe something slightly different from what readers have intuitively understood, across the millennia, the state of pigs to mean; given Plato being what he was and is, we cannot exclude that this is a meaning that is actually portmanteaud with the one that carries the significance at that point in the dialogue, but it is not the precise meaning as intended. But whatever it might mean in context, the scenario of a state of pigs is an obvious and powerful one. The state of pigs is a scenario in which people live on a low, completely virtueand dynamics-free level; they are, however, materially taken care of, and as long as they don't mind living in the mud, and as long as being well fed is all that really matters, it is a nice life for them. So, the idea of the state of pigs is first of all to live a miserable life but a well-fed, non-threatened one in which one's affairs are entirely managed, day to day, by those who own the pigsty.

And that is the catch, of course. Pigs are there to be slaughtered. If you don't pay for your lunch, you are the lunch. Pigs are always the lunch. The entire arrangement is about killing the pigs. A state in which decisions are made, even where services are provided, in a seamless manner is a state of pigs. We are the pigs if we do not decide, if we cannot decide. There is no ambiguity, no subtlety here. It may be that those who own the pigsty and who keep us do so out of benevolence, but how many pigsties are there that are run for the ultimate benefit of the pigs?

Ah, but is that not different in a democracy? Don't the pigs own the sty here, and the farmer works for them? Well, a democracy is where citizens may make decisions, and not only during election time. Whereas the state of pigs is the well-provided-for state in which inhabitants do not make the decisions, but other people do. So the question rather is, not whether seamless service provision is possible in a democracy, but whether democracy isn't defined by provision and decision-making not being carried out in a seamless way. This is so if the seams are where democracy is at.

And this is precisely the promise, or shall we say curse, of the smart city as it really exists, even if only in plans and minds. The entire idea of the smart city is that 
politicians, businessmen and engineers decide for the citizens what is best for them, not needing democratic feedback anymore, let alone legitimacy, because big data supply them with all the information needed to do this in an efficient manner. The point of the smart city is that citizens morph from being subjects to being objects, and that is not an aberration, that is the logical consequence of the entire arrangement, of the concept indeed.

\section{Seamless, data-driven and evidence-based}

That is why seamlessness is part of that unholy trinity of allegedly progressive, but in reality only technologically progressive yet really disenfranchising concepts that have caught the attention of so many government reform initiatives but that have a lethal effect on society and state as they were envisioned for human freedom, autonomy and indeed happiness. (Much of all those iLab, reinventing government and similar well-meaning initiatives share the same problem.) The other two terms are "data-driven" and "evidence-based", because both these concepts suggest that something is objectively true, and thus removed, at least optimally, from human agency. (We have seen this a lot during the pandemic.) But who wants anything data-driven? Data aren't given, we make them. Data never speak, we make them speak. Things are not determined in time and space, as Ernst Cassirer has so impressively shown (1939), but we determine them there. And what is evidence if not a rhetorical device that assigns an interpretation of things, as well? Evidence is not a fact, it just calls things facts and therefore is open to human dialogical agreement. This is particularly problematic as for so many people, evidence is the same as truth because it seems to suggest or imply proof. And this is why the more responsible public policy makers, not least most recently the European Parliament, have moved from data-driven to data-based, from evidence-based to evidence-informed (European Parliament, 2019). It is high time that one moves away from seamlessness as well, seeing that privileging the concept is an implicit attack on human agency, an implied attempt at disenfranchisement, within a system that cannot survive this. 


\section{Explosion}

This disenfranchisement is the logic of our times. But there is a counter-logic against it, one that Juri Lotman has so well described in his last book, called Culture and Explosion (2009). We think that it is written in stone how things will go on, we think that everything will happen exactly as it is predetermined. We always see a Whig Notion of History, linear progress, a development that must be so because right now it looks a certain way. But then, an explosion happens, a disruption, a complete change of course. We thought nothing could or would change, and then it does. This can just "happen", but it can also take the shape of a successful revolt or revolution. When I originally gave this lecture, I used the still ongoing Hong Kong demonstrations and the role of Joshua Wong as an example; during the course of the next months, the COVID-19 pandemic became another, even more powerful one; and right now, the Black Lives Matter protests and radical reform plans, triggered by the killing of George Floyd in May 2020, are the even more impressive phenomenon. Before they happened, nobody would have thought that actions against truly entrenched power structures, or even semi-natural catastrophes that would put the world into a war-like emergency, would be an option. It is just human to extrapolate the few years or decades of normalcy one has just lived through into the futurenow, we really have it, things will stay as they are, and nothing will ever change again. But not so. Therefore, fatalism is not necessary, because one never knows how things will turn out tomorrow.

\section{Resistance}

But if we assume that there will be no revolt against the machine, beyond or better before these explosions-is there a chance to resist seamlessness as disenfranchisement, or better what the disenfranchisement through seamlessness stands for, i.e., the takeover of a techno-financial-political logic of what it means to be an autonomous human being? (Always assuming that this is something that we want, but let's assume this for the moment for the global-Western system.) The pandemic surely has hastened the move into a techno-determined state of coercive control, as the various — if bizarrely late—tracing apps, which will never fully disappear again, have shown. 
So I suggest, for the unnormal normalcy of the tech logic, that there are four ways of how to resist: code, make, talk, and pray.

Code means that engineers never worry that they disenfranchise us, because, even when they are basically sympathetic to the cause of the common person, they are never disenfranchised, because they are always behind the keyboard. In an earlier version of this essay, the editor of the proposed journal reacted very strongly against the suggestion that engineers can be so essentialized. But they can. It is of course not all there is, and not all engineers share this, but this always goes without saying, which is why the essentializing accusation always or almost always is mute. What it means is that it is one variable that many of the people concerned share, and that the logic is there-nothing is monocausal, at least not on this level. That is how in principle and usually, if not always, engineers do act. And the only way how one can counterbalance them is to code as well, because the turf of the ICT age is theirs. In the times in which we live, of course one can try to occupy a non-technological space, but it is very difficult. Just as in politics, if you can't read or write a budget, those who can will always draw you across the table, will always take advantage of you. In our ICT age, if you can't code, the coders will dominate you. This is why it is - and I would certainly say unfortunately-necessary that people, that pupils learn to code, because only that way can they become educated post-user citizens.

Make refers to citizens as true agents within even the smart city. It refers to a true bottom-up approach, it refers to making things both ICT-based and not. And here, the most promising, the most exciting movement surely is that of Commons-Based Peer Production. As others and I have previously argued (Niaros et al., 2017), makerspaces are the spaces in smart cities in which humans can gain genuine agency. It will never be fully easy to give makerspaces and the like the possibility to counter the powers that be with the powers that be, because it is not in the latter's interest to do so, but the chance is there, democracy does give us the chance for such institutions even against the institutionalized will of those that rule, and of course, there are those, and there are not that few, in country and especially city governments who realize that this is a good thing and along the lines of what they should be doing. Makerspaces are the original centers of our time of resistance against seamlessness as disenfranchisement.

Talk means simply to keep the discussion going, not to accept the engineering imperative. A well-known Estonian engineer-bureaucrat-businessman has said, "Estonians are very rational people. We didn't ask. We just forced it. Innovation through pain has always been a key element of change. If the engineers say you 
have to do it this way-it's not a question for debate" (Healthcare IT News, 2018). But we do need to talk. We do need to talk about what really matters, if what we are doing is really leading us there, and if it is not, how we can change things. Of course, there are wicked problems; of course, there are arrangements that people choose although it is against their best interests-many of those indeed. And yes, people do not know what makes them really happy; this is why other traditions than the Western ones, which have an entirely different logic, have come up with institutions that counterbalance this (Drechsler, 2019). But in the global-Western system, discourse matters. Discussion matters. If we are talking about what we want and how to accomplish this, all is not lost. We are not disenfranchised completely as long as we still discuss what we can do against the machine, and nobody stops us.

Pray is probably the most controversial of my points, because both philosophers and engineers don't like the religious side. Jürgen Habermas (2019) has very recently, actually after the speech was originally held, presented us with a magnificent two-volume tome about philosophy and religion in human existence. This is not the place to critically reflect on that book, but one might say that even from a philosophical perspective, religion creates a certain space that is not detrimental, but conducive, to human existence and indeed to human freedom because it, too, potentially counterbalances the machine today (even if it could be, and sometimes is, just as bad). It is, if one will, the flipside of what Andrew D. White's (1897) two-volume magisterial work about the Warfare of Science with Theology in Christendom suggests-if, namely, science is not (only) our friend, which it isn't. In fact, it is science in its applied, simplified form of technology that disenfranchises the human person, and that is precisely why religion can restore freedom. In religious reflection, one realizes what the real priorities of the human person are; it is not simple material welfare, but it is either enlightenment or happiness (both of course are linked, but it would go too far here to delineate why and how this is so). All I would like to say at this point is that through religion, through prayer and what it stands for, there is a gate created that gets us out of the techno-materialist logic that seems to prepare the fertile ground for seamlessness and therefore disenfranchisement. 


\section{Conclusion}

Technological progress doubtless has its good sides; we may only cite, as is always pushed upon us, advances in medicine, even if they are not without problems either, bringing the human desire, as Gadamer has said, of being healthy and living long in juxtaposition (1993). Not for nothing does the ubiquitous Taoist god/saint Shou (the old God of the Morning Star, of the Fu-Lu-Shou trinity) stand for a long and healthy life-by now, technological medicine has actually created a scenario in which one of these categories is fulfilled, but at the sorry price of the other. Technology is always ambivalent, and the risk to overpay for its favors is very high. So if this is not continuously questioned and calibrated, we might miss out on competitiveness and on some progress, but we also might if we don't.

One of the most striking images of where the exploitation of nature, so much at the forefront of our thinking today, leads us is Wagner's Ring. If we abstract from all the shenanigans of gods and heroes, from all the murder and mayhem, what is the story? The Rheingold is at the bottom of the Rhine, protected by the Rhine daughters, and this is where it belongs. It should not be disturbed. Swimming around it and enjoying it is all that may happen. And as soon as the gold is retrieved from the Rhine, disaster commences, culminating in the Götterdämmerung. Peace only returns once the gold is given back to the Rhine, nature, the Rhine daughters bringing it back to the ground where it belongs. Counternarratives to this, explanations of why this is completely nonsense for human development, are a dime a dozen. What is important, however, is that this story is true, as well, and today we might call this degrowth (Hickel, 2020).

Epistemologically speaking, this too is a paper I can close with one of my favorite quotes from the Western Canon, a quote from the fragments of Aristotle, whom we so conveniently left to the side earlier in this text, although he is so often right. And that is that "the good is the most accurate measure of all things" (Aristot. Polit., $\mathrm{R}^{3} 79$, tr. fragm. II in Aristotle, 1952, 68). If we remember that-and if we use that yardstick at any given point-questioning tacit assumptions that only serve to empower the exploiters and to disenfranchise the citizens, already brings us a substantial way forward. It is an uphill battle, but it is not impossible, and perhaps it is not entirely trivial to conclude by saying that recent events, in all their disruptivity, suggest that there is a window for preventing, or at least seriously delaying, seamlessness as disenfranchisement. 


\section{Acknowledgments}

This was the closing keynote for the 15th Estonian philosophy congress in (EFAK XV), delivered at TalTech on 31 August 2019, in the context of the discussions of the establishment of the Smart City Centre of Excellence (FinEst Twins) at TalTech. I thank Amirouche Moktefi and Peeter Müürsepp for the invitation, Margit Sutrop for chairing the plenary session, and all of them as well as the very engaged and engaging audience for critical and crucial feedback. Parts of this lecture, especially the resistance section, were published previously on the Berkman Klein Center blog as Drechsler \& Kostakis, 2020a, and since then also translated into Chinese (Drechsler \& Kostakis, 2020b). For this, I would like to thank my co-author. The current text is based on the recording of a subsequent re-enactment of that keynote in June 2020-which also explains references to later events and publications-, and the speech character has been purposefully retrained. Of course, the manuscript has been edited, and references, especially as regards direct referrals and verbatim quotes, have been added according to good practice. Thanks for excellent comments go, again, to Vasilis Kostakis, to Rainer Kattel and to Ingbert Edenhofer.

\section{References}

Aristotle (1952), The Works of Aristotle 12: Selected Fragments, transl. by Sir D. Ross, Oxford: Oxford University Press.

Cassirer, E. (1939), 'Axel Hägerström. Eine Studie zur schwedischen Philosophie der Gegenwart,' Göteborgs Högskolas Ärsskrift, vol. 45, no. 1, pp. 1-120.

Castells, M. (2009), Communication Power, Oxford: Oxford University Press.

Drechsler, W. (2019), 'Kings and indicators: options for governing without numbers,' in M. J. Prutsch (ed.) Science, Numbers and Politics, Basingstoke: Palgrave Macmillan, pp. 227-261. https://doi.org/10.1007/978-3-030-11208-0_11

Drechsler, W. \& Kostakis, V. (2020a), 'Is the smart city a good city?' Berkman Klein Collection on Medium, 13 February. Retrieved from https://medium.com/berkmanklein-center/is-the-smart-city-a-good-city-233a42bdcd46 [accessed 11 Jun 2020]

Drechsler, W. \& Kostakis, V. (2020b), “智慧城市是好城市吗?' [Is the smart city a good city?] 领导科学论坛 [The Forum of Leadership Studies], no. 8, pp. 5-6.

El Greco (1577-1579), 'The Disrobing of Christ' [oil on canvas]. Retrieved from https://upload.wikimedia.org/wikipedia/commons/2/25/El_Expolio\%2C_por_El_ Greco.jpg [accessed 11 Jun 2020] 
European Parliament (2019), "Scientific Evidence" and "Expert Knowledge" in Contemporary Policy-Making' workshop, Brussels, 21 May.

Gadamer, H.-G. (1934), Plato und die Dichter, Frankfurt am Main: Klostermann.

Gadamer, H.-G. (1993), Über die Verborgenheit der Gesundheit, Frankfurt am Main: Suhrkamp.

Habermas, J. (2019), Auch eine Geschichte der Philosophie, 2 vols., Frankfurt am Main: Suhrkamp.

Healthcare IT News (2018), “'We didn't ask. We just forced it." Estonian e-government pioneer says there is no innovation without pain,' 17 May. Retrieved from https:// www.healthcareit.com.au/article/\%E2\% 80\%9Cwe-didn\%E2\%80\%99t-askwe-just-forced-it $\%$ E2\%80\%9D-estonian-e-government-pioneer-says-there-noinnovation [accessed 11 Jun 2020]

Hickel, J. (2020), 'What does degrowth mean? A few points of clarification,' Globalizations, in press. https://doi.org/10.1080/14747731.2020.1812222

Jünger, F. G. (1949), Die Perfektion der Technik, 2nd augmented ed., Frankfurt am Main: Klostermann.

Kant, I. (1784), 'Beantwortung der Frage: Was ist Aufklärung?' Berlinische Monatsschrift, vol. 12, pp. 481-494.

Lotman, J. (2009), Culture and Explosion, Berlin: Mouton de Gruyter.

Niaros, V.; Kostakis, V. \& Drechsler, W. (2017), 'Making (in) the smart city: the emergence of makerspaces,' Telematics and Informatics, vol. 34, no. 7, pp. 1143-1152. https://doi.org/10.1016/j.tele.2017.05.004

Perez, C. (2002), Technological Revolutions and Financial Capital: The Dynamics of Bubbles and Golden Ages, Cheltenham: Edward Elgar. https://doi.org/10.4337/9781781005323

White, A. D. (1896), A History of the Warfare of Science with Theology in Christendom, 2 vols., London: Macmillan.

Wikipedia (n. d.), 'Seamless robe of Jesus.' Retrieved from https://en.wikipedia.org/wiki/ Seamless_robe_of_Jesus [accessed 11 Jun 2020]

Yeo, D. (2019), 'Public sector transformation,' Paper presented at Plenary Session on Transformational Governance organized by the Civil Service College, Singapore, IIAS-Lien 2019 Conference, Nanyang University of Technology, 19 June.

Zuboff, S. (2019), The Age of Surveillance Capitalism: The Fight for a Human Future at the New Frontier of Power, New York: Public Affairs.

Wolfgang Drechsler is professor of governance at Tallinn University of Technology's Ragnar Nurkse Department and member of the governance stream of the FinEst Twins Smart City Center of Excellence, honorary professor of University College London in the Institute of Innovation and Public Purpose, 
and associate and member of the advisory board at Harvard University's Davis Center. Since 2020, he also serves as the chair of the executive board of EAPAA, the European Association for Public Administration Accreditation. In civil service, he has been advisor to the President of Estonia, executive secretary with the German Wissenschaftsrat, and, as an APSA congressional fellow, senior legislative analyst in the United States Congress. His main academic interests are public management, technology, and innovation; nonWestern public administration; and public management reform generally; but he also retains a special interest in political philosophy and semiotics. One of the last students of Hans-Georg Gadamer, and an elected member of the International Plato Society, he has also frequently written, in the Western philosophical tradition, about Xenophanes, Lorenzetti, Wolff, and Nietzsche. For his five-volume edition of the works of Johann Ulrich v. Cramer (within Wolff's Gesammelte Werke), he received the 1997 Estonian National Science Award, social sciences category. 